\title{
PLASMA NUTFAH HIJAUAN PAKAN TERNAK SEBAGAI SUMBER BIBIT DAN VISITOR PLOT
}

\author{
Rijanto Hutasoit, Juniar Sirait dan Andi Tarigan \\ Loka Penelitian Kambing Potong, PO Box I Sungei Putih, Galang 20585, Sumatera Utara \\ (085261038444, email h.rijanto@yahoo.com)
}

\begin{abstract}
ABSTRAK
Keterbatasan informasi untuk mendapatkan bibit dan pengetahuan dalam budidaya merupakan salah satu hambatan dalam pelaksanaan pengembangan hijauan pakan ternak. Salah satu sumber bibit yang dapat membantu kebutuhan masyarakat terdapat di Loka penelitian Kambing Potong Sei Putih Sumatera Utara. Berbagai jenis tanaman pakan ternak dipelihara dan merupakan suatu Plasma nutfah hijauan pakan ternak, terdapat 85 spesies hijauan yang terdiri dari 40 jenis rumput dan 45 jenis Leguminosa. Kegiatan tersebut dilaksanakan pada tahun 1997 dan ditetapkan sebagai visitor plot pada tahun 2000. dengan rata-rata pengunjung sebanyak 80 orang per tahun yang terdiri dari Petani, Penyuluh dan Mahasiswa. Plasma nutfah bermanfaat sebagai sumber bibit, bagi pengguna yang ingin menanam hijauan pakan ternak dapat memperolehnya sesuai dengan jenis dan kriteria yang diinginkan. Saat ini terdapat 90 Ha luas lahan yang dikembangkan dari Plasma nutfah tersebut, beberapa hijauan diantaranya yang telah di Introduksi dengan kriteria produksi tinggi, mudah tumbuh, disukai ternak dan tahan kemarau seperti : Paspalum atratum, Paspalum gueonarum, Braciaria ruziziensis, Brachiaria humidicola, Brachiaria brizantha, Stenotaphrum secondatum, Kinggrass, Stylosanthes guianensis CIAT 184, Arachis pintoi, Arachis glabrata, dan Indigofera.
\end{abstract}

\section{Kata kunci : Plasma nutfah, Visitor plot, Introduksi}

\begin{abstract}
Lack of information to get the seeds and knowledge in cultivation is one of the obstacles in the implementation of the development of forage. One source of seeds that can assist in the Goat Research Station, Sei Putih North Sumatra. Various types of fodder crops maintained was an forage Germplasm, there are 85 species of forage consisting of 40 grass species and 45 types of Legume. The activity was held in 1997 and designated as visitor plots in 2000 with an average of 80 visitors per year consisting of Farmers, Extension and Students. Germplasm useful as sources of seed, for users who want to plant forage can get it according to the type and desired criteria. Currently there are $90 \mathrm{Ha}$ of land that is developed from the Germplasm, some of forage have been Introductions with criteria of high production, easy to grow, palatable and drought resistant as: Paspalum atratum, Paspalum gueonarum, Braciaria ruziziensis, Brachiaria humidicola, Brachiaria brizantha, Stenotaphrum secondatum, Kinggrass, Stylosanthes guianensis CIAT 184, Arachis pintoi, Arachis glabrata, murberry and Indigofera.
\end{abstract}

Keywords: Germplasm, Visitor plot, Introductions.

\section{PENDAHULUAN}

Hijauan Pakan Ternak adalah rumput dan leguminosa alami atau yang dibudidayakan dan merupakan bahan makanan utama ruminansia seperti kerbau, sapi, kambing dan domba untuk memenuhi kebutuhan hidup pokok, produksi dan reproduksinya (Atwood et al., 2001). Pengembangannya perlu mendapat perhatian karena setiap kenaikan jumlah populasi ternak tidak di ikuti oleh peningkatan areal penanaman hijauan.

Kelemahan sistem produksi peternakan juga terletak pada tatalaksanan pakan dan kesehatan (Barnes dan Baylor, 1995) keterbatasan pakan dapat menyebabkan populasi ternak disuatu daerah menurun. Oleh karena itu kemampuan peternakan dalam penyediaan pakan akan menentukan jumlah ternak yang mampu dipeliharanya (Stur dan Horne, 2001). Menurut Santoso (1989) ternak besar seperti sapi dan kerbau akan mengkonsumsi hijauan sebesar 10\% dari berat badannya atau sekitar 20-25 Kg/ekor/hari sedangkan ternak kecil (kambing dan domba) dapat menghabiskan hijauan antara 5-7 kg/ekor/hari. Dengan kebutuhan tersebut tentunya sangat diperlukan penyediaan pakan yang cukup dan berkesinambungan.

Sebenarnya banyak petani/peternak yang ingin menanam pastura, namun karena keterbatasan informasi untuk mendapatkan bibit dan pengetahuan dalam pemeliharaan merupakan salah satu hambatan dalam pelaksanaannya. Salah satu sumber bibit yang dapat membantu kebutuhan masyarakat terdapat di 
Loka penelitian Kambing Potong Sei Putih Sumatera Utara, terdapat berbagai jenis tanaman pakan ternak dipelihara dan merupakan suatu Plasma nutfah yang dijaga dan dirawat guna mempertahankan kelangsungan hidup setiap spesiesnya.

Tujuan penulisan ini untuk memberikan informasi kepada petani, mahasiswa, penyuluh dan masyarakat untuk dapat mengenal beberapa jenis rumput unggul (budidaya) dan memperoleh bibit guna mendorong minat dalam mencoba menerapkan teknologi hijauan pakan ternak dan menghilangkan ketergantungan pada tanaman pakan ternak alami.

\section{Hambatan dalam pengembangan hijauan pakan}

Keterbatasan bibit rumput merupakan hambatan dalam pembangunan pastura, kurangnya instansi Pemerintah dibidang peternakan, baik ditingkat Provinsi maupun Kabupaten / Kota yang dapat memberikan pelayanan kepada masyarakat untuk memenuhi kebutuhan bibit rumput merupakan hambatan dalam pengembangan pastura, dan kurangnya binaan maupun pengetahuan petugas penyuluh tentang hijauan pakan ternak juga merupakan faktor lambatnya proses adopsi hijauan pakan ternak.

Adinugraha et al. (2002) tersedianya bibit dalam pembangunan pastura akan menentukan jumlah luas lahan yang akan ditanami. Banyaknya petani yang ingin menanam dan mengembangkannya namun ketersediaanya sangat terbatas, sehingga untuk memperoleh rumput dalam memenuhi kebutuhan ternak petani harus mencari ke areal perkebunan karet/sawit, pematang sawah dan pinggiran-pinggiran aliran sungai yang letaknya 4-5 km dari kandang dan memakan waktu 2-3 jam setiap harinya, dengan masalah yang dihadapi yaitu jalan yang ditempuh sulit dilewati terutama pada musim hujan, dan semakin banyaknya saingan petani peternak lainnya yang mencari rumput, sehingga semakin lama persediaan rumput dilokasi tersebut semakin berkurang, sedangkan pada musim kemarau produksi rumput menurun dan lahan-lahan untuk pengembalaan ternak kekeringan, karena kandungan air dalam tanah menurun hal ini diamati oleh (Knipscheer et al., 1994; Prawirodigdo et al., 2004), banyak lahan yang tidak dapat digembalakan sehingga mengakibatkan turunnya produktivitas ternak.

\section{Gambaran Umum Plasma Nutfah Hijauan Pakan Ternak}

Plasma nutfah yaitu mengkoleksi suatu jenis/ Spesies/Genus/Famili/Bangsa yang murni untuk dipertahankan kelangsungan hidupnya. Oleh karena itu Plasma nutfah hijauan perlu mendapat perhatian agar tidak punah dengan melakukan perawatan seperti: Penyiangan, pemupukan, penyisipan tanaman yang mati, pemotongan (panen) yang teratur.

Plasma nutfah hijauan pakan ternak di Kebun Percobaan Loka Penelitian Kambing Potong Sei Putih Sumatera Utara dibangun pada tahun 1997 dan ditetapkan sebagai Visitor Plot pada tahun 2000 dengan jumlah tanaman sebanyak 85 spesies yang terdiri dari 40 jenis rumput dan 45 jenis leguminosa yang berasal dari rumput lokal yang ada di Indonesia dan berbagai negara seperti : Brazil, Venozuela, Afrika utara, Mexico, Thailand dan negara-negara lainnya.

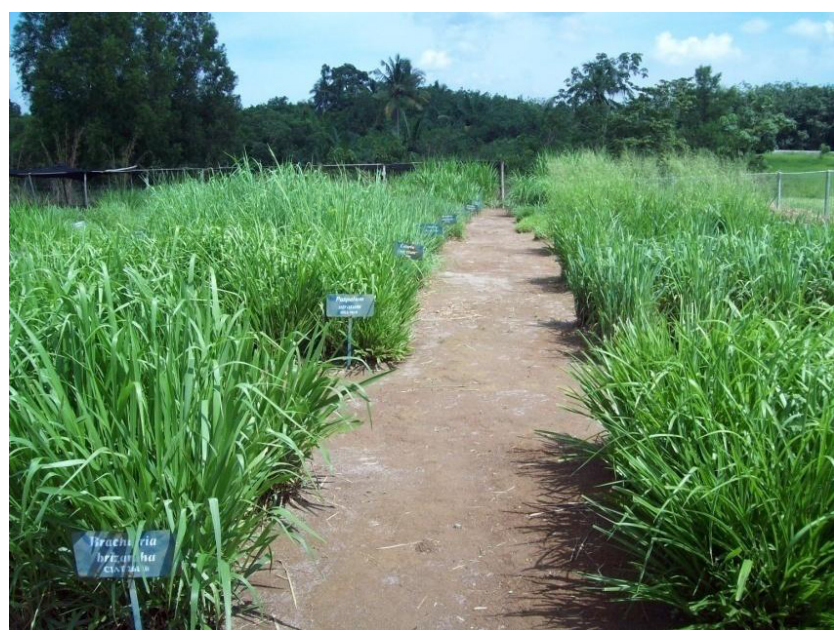

Gambar 1. Plasma nutfah hijauan pakan ternak

Beberapa penelitian telah dilakukan pada Plasma nutfah yang menghasilkan data produksi dan pengaruh lingkungan pertumbuhan tanaman. Dari data tersebut beberapa spesies ditetapkan sebagai tanaman Introduksi yang produksinya cukup tinggi dengan adaptasi lingkungan yang baik dan pengembangannya dapat dilakukan hampir pada semua Agro Ekosistem, seperti: Paspalum atratum, Paspalum gueonarum, Brachiaria ruziziensis, Stenotaphrum secondatum, Kinggrass, Stlosanthes guianensis CIAT 184, Arachis glabrata, Indigofera dan Murbery (murbei). Jenisjenis hijauan yang terdapat pada Plasma nutfah hijauan pakan ternak Loka Penelitian Kambing Potong Sei Putih.

\section{PROSPEK PLASMA NUTFAH HIJAUAN PAKAN TERNAK}

\section{Sebagai Sumber Bibit}

a. Pembangunan pastura

Ketersediaan bibit penting dalam pengembagan pastura (Guo et al., 2007). Plasma nutfah hijauan pakan ternak sebagai sumber bibit sangat bermanfaat bagi petani yang ingin menanam rumput dengan berbagai jenis yang mereka inginkan, sehingga rumput dengan mudah dapat diperoleh karena dekat dengan kandang ternak, waktu dan tenaga tenaga yang dibutuhkan tidak begitu banyak dan kebutuhan ternak akan rumput dapat mencukupi.

Persiapan bibit dalam pembangunan pastura perlu diketahui terlebih dahulu materi tanam setiap jenis hijauan dan lama penyimpanan agar bibit tidak rusak/busuk (Doos, 2000). Misalnya untuk untuk jenis rumput umumnya bahan tanam yang digunakan berupa pols (anakan) lama penyimpanan 2-3 hari dan 
Tabel 1. Jenis Rumput (Graminae)

\begin{tabular}{|c|c|c|}
\hline No. & Spesies & Kultivar \\
\hline 1. & Andropogon gayanus & Kent \\
\hline 2. & Andropogon gayanus & 621 \\
\hline 3. & Brachiaria brizantha & \\
\hline 4. & Brachiaria brizantha & 6780 \\
\hline 5. & Brachiaria brizantha & 6387 \\
\hline 6. & Brachiaria brizantha & 26110 \\
\hline 7. & Brachiaria brizantha & FSP 1 \\
\hline 8. & Brachiaria brizantha & 16835 \\
\hline 9. & Brachiaria brizantha & 16318 \\
\hline 10. & Brachiaria dictyoneura & 6133 \\
\hline 11. & Brachiaria decumbens & Basilisk \\
\hline 12. & Brachiaria humidicola & 6133 \\
\hline 13. & Brachiaria humidicola & 16886 \\
\hline 14. & Brachiaria humidicola & CV Tully \\
\hline 15. & Brachiaria humidicola & 2639 \\
\hline 16. & Brachiaria ruziziensis & \\
\hline 17. & Digitaria milanjiana & 40700 \\
\hline 18. & Digitaria milanjiana & Jarra \\
\hline 19. & Digitaria smutsii & Premer \\
\hline 20. & Ottocloa nodusa & \\
\hline 21. & Paspalum atratum & 9610 \\
\hline 22. & Paspalum atratum & FSP2 \\
\hline 23. & Paspalum atratum & Pantaneira \\
\hline 24. & Paspalum conjugatum & \\
\hline 25. & Paspalum dilatatum & \\
\hline 26. & Paspalum gueonarum & 3824 \\
\hline 27. & Paspalum notatum & \\
\hline 28. & Paspalum plicatulum & \\
\hline 29. & Panicum maximum & 6299 \\
\hline 30. & Panicum maximum & T58 \\
\hline 31. & Panicum maximum & Hamil \\
\hline 32. & Panicum maximum & Petrie \\
\hline 33. & Panicum maximum & Purpleguenea \\
\hline 34. & Panicum maximum & Riversidale \\
\hline 35. & Penisetum purpureum & King \\
\hline 36. & Penisetum purpureum & CV moot \\
\hline 37. & Setaria spacelata & Splendida S \\
\hline 38. & Setaria spacelata & olander \\
\hline 39. & Stenotaphrum secondatum & \\
\hline 40. & Cynodon & Plectotacine \\
\hline
\end{tabular}

stek (batang) bisa mencapai 4-5 hari.sedangkan untuk jenis leguminosa bahan tanam yang digunakan berupa biji-bijian penyimpanan dapat lebih lama 2-3 tahun dan legum yang membentuk stolon/rizoma (batang yang menjalar di atas/di bawah tanah) dapat bertahan 2-3 hari. Untuk bibit yang berupa pols, stek, stolon dan rizoma, sebelum ditanam sebaiknya bibit disimpan pada lokasi yang teduh dan lembab terhindar dari sinar matahari agar bibit tidak sampai kering pada saat penanaman.

Menurut Hartadi et al. (2005) dalam usaha pengembangan hijauan pakan ternak pada suatu areal penanaman perlu persiapan bibit agar tidak kurang atau berlebihan pada saat penanaman, yaitu dengan cara mengetahui terlebih dahulu luas lahan yang akan ditanam, kemudian dibagi dengan jarak tanam penanaman. Misalnya : Penanaman rumput Paspalum atratum.

- Luas lahan 1 ha $=10.000 \mathrm{~m}^{2}$

- Jarak tanam 0,5 x 0,5 m = 0,25 $\mathrm{m}^{2}$

- Maka jumlah bibit yang dibutuhkan $=10.000 \mathrm{~m}^{2}$ : $0,25 \mathrm{~m}^{2}=40.000$ pols.

Untuk jenis leguminosa penanaman umumnya
Tabel 2. Jenis Legum (Leguminoseae)

\begin{tabular}{|c|c|c|}
\hline No. & Spesies & Kultivar \\
\hline 1. & Arachis pintoi & Amarillo \\
\hline 2. & Arachis pintoi & 22160 \\
\hline 3. & Arachis pintoi & 18744 \\
\hline 4. & Arachis pintoi aupila & 17434 \\
\hline 5. & Arachis sp & Ex maiwa \\
\hline 6. & Arachis sp & CPI 12121 \\
\hline 7. & Arachis glabrata & Foligrace \\
\hline 8. & Arachis glabrata & IRFL 3041 \\
\hline 9. & Arachis glabrata & IRFL 3053 \\
\hline 10. & Arachis glabrata & IRFL 3015 \\
\hline 11. & Arachis glabrata & IRFL 3059 \\
\hline 12. & Arachis glabrata & IFRL 3062 \\
\hline 13. & Arachis glabrata & IRFL 3046 \\
\hline 14. & Arachis glabrata & IRAL 3099 \\
\hline 15. & Arachis glabrata & IRAL 3080 \\
\hline 16. & Arachis glabrata & IRAL 3043 \\
\hline 17. & Centrocema acutifolium & CIAT 5277 \\
\hline 18. & Centrocema caeruleum & 77304 \\
\hline 19. & Centrocema hybrid & CIAT 442 \\
\hline 20. & Centrocema macrocarphum & 25522 \\
\hline 21. & Centrocema pubescens & 15160 \\
\hline 22. & Centrocema macrocarphum & CIAT 1504 \\
\hline 23. & Chamaecrista rotundifolia & Wynn \\
\hline 24. & Clitoria ternatea & \\
\hline 25. & Desmodium rensonii & 46562 \\
\hline 26. & Flemingia macrophylla & 17403 \\
\hline 27. & Peuraria phaseoloides & 32118 \\
\hline 28. & Stylosanthes hamata & CV amiga \\
\hline 29. & Stylosanthes guianensis & FSP 4 \\
\hline 30. & Stylosanthes guianensis & CIAT 184 \\
\hline 31. & Stylosanthes guianensis & CV cook \\
\hline 32. & Stylosanthes guianensis & FM 05-1 \\
\hline 33. & Stylosanthes guianensis & FM 05-2 \\
\hline 34. & Stylosanthes guianensis & FM 05-3 \\
\hline 35. & Stylosanthes guianensis & FM 07-1 \\
\hline 36. & Stylosanthes guianensis & FM 07-2 \\
\hline 37. & Stylosanthes guianensis & FM 07-3 \\
\hline 38. & Stylosanthes guianensis & CIAT 21 \\
\hline 39. & Zornia latifolia & 728 \\
\hline 40. & Indigofera sp & \\
\hline 41. & Leucaena leucochepala & K 636 \\
\hline 42. & Murberry & Nigra \\
\hline 43. & Murberry & Indica \\
\hline 44. & Murberry & Catayana \\
\hline 45. & Medicago sativa & \\
\hline
\end{tabular}

menggunakan biji seperti: Stylosanthes guianensis CIAT 184, Centrocema, dan Calopogonium Muconoides, biji yang dibutuhkan sebanyak 4-7 kg/ha.

b. Pedoman Jarak Tanam Hijauan Pakan Ternak Jarak tanam salah satu faktor penting yang mempengaruhi perkembangan dan produksi tanaman (Kabi dan Bareeba, 2007). Beberapa rekomendasi jarak tanam yang di lakukan adalah:

- Rumput yang tumbuh pendek jarak tanam $=0,3^{-}$ 0,5 m x 0,3-0,5 m. Misalnya: Paspalum atratum, Paspalum gueonarum, Setaria, Paspalum dilataum, Braciaria ruziziensis dan Digitaria milanjiana.

- Rumput potongan yang tumbuh tinggi vertikal berumpun, jarak tanam o,6-0,9 $\mathrm{m} \times 0,5-0,6$ m. Misalnya: Panicum maximum, Kinggrass, Penisetum purpureum dan Andropogon gayanus. 
Tabel 3. Beberapa produksi tanaman hijauan hasil penelitian di Loka Penelitian Kambing Potong Sei Putih

\begin{tabular}{clc}
\hline No. & \multicolumn{1}{c}{ Nama Hijauan } & Produksi /ha /thn \\
\hline 1. & Brachiaria brizantha 26110 & 93,5 ton \\
2. & Setaria spacelata, splendia & 116,4 ton \\
3. & Paspalum atratum, 9610 & 110 ton \\
4. & Brachiaria decumbens, basilisk & 55,6 ton \\
5. & Penisetum purpureum, king & 160 ton \\
6. & Andropogon gayaus, kent & 150 ton \\
7. & Digitaria milanjiana, jarra & 50 ton \\
8. & Panicum maximum, T58 & 90 ton \\
9. & Brachiaria humidicola, 6133 & 96 ton \\
10. & Brachiaria ruziziensis & 120 ton \\
11. & Stenotaphrum secondatum & 90 ton \\
12. & Arachis pintoi, amarillo & 12,8 ton \\
13. & Stylosanthes guianensis, CIAT 184 Cen- & 58 ton \\
& trocema pubescens & \\
14. & Arachis glabrata & 36,7 ton \\
15. & Indigofera & 18 ton \\
16. & Murberry, indica & 90 ton \\
17. & & 60 ton \\
\hline
\end{tabular}

- Rumput yang membentuk stolon atau rizoma, jarak tanam o,6 x 0,9 m. Misalnya: Arachis pintoi dan Arachis glabrata.

- Rumput untuk padang pengembalaan dengan jarak tanam yang lebih dekat $0,3 \times 0,3 \mathrm{~m}$. akan mempercepat rumput menutupi lahan sehingga lebih cepat dapat dimanfaatkan. Misalnya: Brachiaria brizantha, brachiaria humidicola dan digitaria milanjiana.

\section{Sebagai Visitor Plot}

a. Visitor Plot Sebagai koleksi Beberapa Jenis Hijauan Pakan Ternak

Adapun tujuan dari visitor plot adalah sebagai tempat koleksi dan dapat difungsikan sebagai media desiminasi guna mempercepat penyebarluasan suatu teknologi dan secara langsung dapat mempercepat proses adopsi.

Preferensi masyarakat dalam mengadopsi teknologi hijauan pakan ternak masih sangat rendah, antara lain karena sisitem peternakan di Indonesia umumnya masih dilakukan secara tradisional sehingga untuk memproduksi daging dalam jumlah besar menjadi lambat (McDonald et al., 1988). Upaya untuk mengatasi masalah ini antara lain menimbulkan keinginan petani untuk mengadopsi hijauan pakan ternak dengan menyediakan bibit hijauan yang produksinya tinggi, mudah tumbuh, beradaptasi dengan baik dan disukai oleh ternak.

Plasma nutfah hijauan pakan ternak sebagai Visitor plot digunakan juga sebagai metode tempat pelatihan yang dapat meningkatkan pengetahuan dan keterampilan petani dalam teknologi pengembangan hijauan. Sehingga dapat merubah prilaku, menambah kesanggupan petani dalam meningkatkan efesiensi usaha taninya.

\section{b. Manfaat Visitor Plot}

Hasil dari kunjungan Visitor plot telah banyak menimbulkan minat petani untuk merubah prilaku. Beberapa pengunjung mendemonstrasikan pada lahan usaha taninya, lahan tidur / kosong, dan tanah kritis, telah dimanfaatkan sebagai tempat pengembangan hijauan dan tempat pangonan ternak dalam meningkatkan efesiensi usaha tani.

Sampai saat ini tercatat sebanyak 1100 orang pengunjung yang terdiri dari petani 330 orang, kontak tani 220 orang, pengusaha 50 orang, dan mahasiswa 500 orang. Dari hasil kunjungan tersebut telah dikembangkan seluas 90 Ha luas lahan yang tersebar dibeberapa daerah Sumatera Utara. Misalnya : Kabupaten Deliserdang, Tanah Karo, Tapanuli Selatan, Tapanuli Utara dan Mandailing Natal, Asahan, Serdang bedagei. Dan provinsi lainnya seperti : Aceh, Jambi, Riau, Sumatera Barat, Yogyakarta, Jawa Barat, Sulawesi Utara, Kalimantan Tengah, kalimantan Barat dan NTT.

\section{SIMPULAN}

Plasma Nutfah bermanfaat sebagai sumber bibit bagi petani/ masyarakat yang ingin menanam hijauan pakan ternak dengan berbagai jenis yang mereka inginkan, sebanyak 85 spesies yang ada didalamnya dan pengembangannya sudah mencapai $90 \mathrm{Ha}$. Sebagai Visitor plot telah banyak dikunjungi, sampai saat ini tercatat sebanyak 1100 orang pengunjung terdiri dari petani, kontak tani, pengusaha dan mahasiswa dan hasil kunjungan dapat merubah prilaku dalam meningkatkan efesiensi usaha tani dengan mengadopsi teknologi hijauan pakan ternak. Dari sekian banyak spesies terdapat 12 spesies hijauan Introduksi yang pengembangannya dapat dilakukan hampir pada semua agroekosistem seperti : Paspalum atratum, Paspalum gueonarum, Brachiaria brizantha, Brachiaria ruziziensis, Brachiaria humidicola, Stenotaphrum secondatum, Kinggrass, Stylosanthes guianensis CIAT 184, Arachis pintoi, Arachia glabrata, Indigofera dan Murberry.

\section{SARAN}

Dengan adanya Plasma nutfah hijauan pakan ternak para petani/peternak dapat memanfaatkannya dalam pengembangan hijauan yang luas lagi dengan berbagai jenis, sehingga dapat mencukupi kebutuhan ternak setiap hari dari lahannya sendiri. Sebaiknya plasma nutfah hijauan tetap dipelihara dan dipertahankan kelangsungan hidupnya agar menjadi sumber bibit yang dapat digunakan setiap saat.

\section{DAFTAR PUSTAKA}

Atwood,S.B., FD.Frovenza, R.D. Wiedmeier and R.E. Banner. 2001. Influence of free choice vs mixed-ration diets on food intake and performance of fattening calves. J. Anim. Sci. 79: 3034-3040.

Adinugraha, A.H., P. Sugeng, M. Hidayat dan Mahfud. 2002. Studi variansi pertumbuhan stek beberapa jenis murbei (Morus sp). Buletin Penelitian Pemuliaan Pohon. Vol. 6 : 1. 
Barnes, R.F and J.E. Baylor. 1995. Forages in a changing world. In: Forages, Vol 1: An intoducion to Grassland Agriculture, Barnes R.F., Miller D.A.and C.J. Nelson (eds.) $5^{\text {th }}$ ed. Iowa State University Press, Iowa.

Doss, S.G., Vijayan, K. Rahman, M.S. Das , K.K. Chakraborti, and B.N. Roy. 2000. Effect of plant density on growth, yield and leaf quality in triploid mulberry. Sericologia, 4O(1): 175-180.

Guo, Z.W., C. Tingting, Y. Yonghua and P. Le. 2007. A preliminary analysis of a sexual genetic variability in mulberry as revealed by ISSR markers, Int. J. Agri. Biol., 9(6), 928-930.

Hartadi, H., S. Reksohadiprodjo dan A.D. Tilman. 2005. Tabel komposisi pakan untuk Indonesia. Cetakan kelima Gadjah Mada University Press, Yogyakarta.

Kabi, F. and F.B. Bareeba. 2007. Herbage biomass production and nutritive value of mulberry (Morus indica) and Calliandra calothyrsus harvested at different cutting frequencies, Anim. Feed Sci. Technol. doi:10.1016/ j.anifeedsci.2007.02.011 (in press).
Knipscheer, H.C., H.W. Shwu-eng and A. Mulyadi. 1994. Opportunities for commercialization of small ruminant production in Indonesia. Proc. Of simposium held in conjuction with $7^{\text {th }}$ Asian-Australian Assonimal Societies conggress Small Ruminat Colaburative Research Suppor Program. Unuversity of Calivornia Davis, USA.

McDonald, P., R.A. Edwards dan J.FD. Greenhalgh. 1988. $4^{\text {th }}$ Ed. Longman scientific and Tecnical, Harlow.

Prawirodigdo, S., T. Herawati dan B. Uromo. 2004. Perspektif efisien penggunaan bahan pakan lokal dalam perbaikan usaha ternak domba oleh petani miskin di Desa Oagergunung, Kabupaten Temanggung. Pros. Seminar Nasional Pemberdayaan Petani Miskin dilahan Marginal melalui Inovasi Tepat Guna. Mataram, Nusa Tenggara Barat, Puslitbang Sosial Ekonomi Pertanian. Bogor. Hlm.235-241.

Santoso, BT. 1989. Farm Forestri penyediaan hijauan makanan ternak. Poultry Indonesia. No 118 th ke X. Hal : 47-50.

Stur, W.W. and P.M. Horne. 2001. Mengembangkan teknologi hijauan makanan ternak bersama petani kecil. Penerjemah Maimunah tuhulele, Tatang Ibrahim, ditenerbitkan oleh ACIAR dan CIAT. Monograf ACIAR No. 90. 